\section{(2) OPEN ACCESS}

\title{
Managing vitamin D deficiency in inflammatory bowel disease
}

\author{
Ole Haagen Nielsen, ${ }^{\circ}{ }^{1}$ Thomas Irgens Hansen, ${ }^{1}$ John Mark Gubatan, ${ }^{2}$ \\ Kim Bak Jensen, ${ }^{3,4}$ Lars Rejnmark ${ }^{5}$
}

\begin{abstract}
Management of inflammatory bowel disease (IBD), including ulcerative colitis and Crohn's disease, is generally cumbersome for patients and is a massive health-economic burden. In recent years, the immunomodulating effects of vitamin $D$ have gained a huge interest in its possible pathogenic influence on the pathophysiology of IBD. Vitamin D deficiency is frequent among patients with IBD. Several clinical studies have pointed to a critical role for vitamin D in ameliorating disease outcomes. Although causation versus correlation unfortunately remains an overwhelming issue in the illusive chicken versus egg debate regarding vitamin $D$ and IBD, here we summarise the latest knowledge of the immunological effects of vitamin D in IBD and recommend from available evidence that physicians regularly monitor serum 25(OH)D levels in patients with IBD. Moreover, we propose an algorithm for optimising vitamin D status in patients with IBD in clinical practice. Awaiting well-powered controlled clinical trials, we consider vitamin D supplementation to be an affordable and widely accessible therapeutic strategy to ameliorate IBD clinical outcomes.
\end{abstract}

\section{INTRODUCTION}

Patients with inflammatory bowel disease (IBD; ie, ulcerative colitis and Crohn's disease) are at risk of developing extraintestinal manifestations like osteopenia and osteoporosis due to several factors, including vitamin $\mathrm{D}$ deficiency. ${ }^{1}$ However, apart from classical effects on bone mineralisation, vitamin $\mathrm{D}$ also has distinct immunological functions influencing cell proliferation and differentiation, immunomodulation and the gut microbiome and, recently, its deficiency has been implicated in the development of anaemia of chronic disease. ${ }^{2-4}$ In vitro studies have identified a number of mechanisms by which the biological active form of vitamin $\mathrm{D}, 1,25(\mathrm{OH})_{2} \mathrm{D}$, may reduce inflammation. ${ }^{5}$ For example, treatment with $1,25(\mathrm{OH})_{2} \mathrm{D}$ suppresses the nuclear factor kappa light chain enhancer of activated $\mathrm{B}$ cells $(\mathrm{NF}-\kappa \mathrm{B})$ pathway, thereby reducing downstream expression of proinflammatory cytokines, ${ }^{6}$ and by acting as a ligand-activated transcription factor, the vitamin D receptor (VDR) directly regulates cytokine gene expression. ${ }^{7}$

These observations have facilitated a huge interest in the possible pathogenic influence of vitamin $\mathrm{D}$ on the clinical course of IBD, especially as a growing body of evidence has suggested that high concentrations of circulating proinflammatory biomarkers, for example, interleukin-6, tumour necrosis factor (TNF)- $\alpha$ and $C$ reactive protein (CRP) are linked with vitamin $\mathrm{D}$ deficiency ${ }^{8}$ and that anti-inflammatory cytokine levels are downregulated during summer in association with increased serum (s)-25(OH)D levels. ${ }^{9}$ Moreover, vitamin D deficiency is more frequent in IBD as compared with the general population, especially in Crohn's disease. ${ }^{10}$

Consistent with this knowledge, several clinical studies have been performed linking vitamin D levels with meaningful clinical outcomes in IBD. ${ }^{11-13}$ Independent of other variables, lower vitamin $\mathrm{D}$ levels associates with a greater risk of clinical relapse. ${ }^{13-15}$ Vitamin D insufficiency may increase the risk of flaring IBD, as it is a negative modulator of proinflammatory cascades, causing intestinal epithelial barrier defects, an escalated immune response and intestinal destruction. ${ }^{16}$

The aim of the present paper is to summarise current evidence as well as propose a practical guideline based on recent clinical studies on how to manage vitamin $\mathrm{D}$ deficiency in patients with IBD in the clinical setting. 


\section{MECHANISMS BEHIND ACTION OF VITAMIN D}

Vitamin D is a fat-soluble secosteroid hormone with endocrine and autocrine functions. The primary endocrine function of vitamin $\mathrm{D}$ is the maintenance of calcium homeostasis and bone metabolism. ${ }^{3}$ The autocrine function of vitamin D depends on genetic transcription unique to the cell type expressing the vitamin $\mathrm{D}$ receptor (VDR). One such autocrine effect is the modulation of inflammatory pathways, which plays a role in several diseases, including IBD.

Serum levels of $25(\mathrm{OH}) \mathrm{D}$ are used to define vitamin $\mathrm{D}$ deficiency and are considered as the best indicator of body stores of vitamin D. The threshold for levels of 'deficiency' are largely based on physiological levels required to avoid elevated levels of parathyroid hormone and to maintain bone health, and even these remain a contentious issue in the scientific literature. ${ }^{3}$ Some expert recommendations, including a statement from The Endocrine Society, consider s-25(OH)D levels below $50 \mathrm{nmol} / \mathrm{L}$ (ie, $20 \mathrm{ng} / \mathrm{mL}$ ) as deficiency and levels in the range of $50-75 \mathrm{nmol} / \mathrm{L}(20-30 \mathrm{ng} / \mathrm{mL})$ as insufficiency. ${ }^{17}$ However, the US Institute of Medicine (now the National Academy of Medicine) defines deficiency as a s-25(OH)D level below $30 \mathrm{nmol} / \mathrm{L}(12 \mathrm{ng} /$ $\mathrm{mL}$ ) and insufficiency as $25(\mathrm{OH}) \mathrm{D}$ levels in the range of $30-50 \mathrm{nmol} / \mathrm{L}(12-20 \mathrm{ng} / \mathrm{mL}){ }^{3}{ }^{18}$ This cut-off is, however, based on population-based studies in the USA focused on bone health, and it has been suggested that immunomodulatory and other non-skeletal effects benefit from even higher concentrations (ie, $75 \mathrm{nmol} / \mathrm{L})^{17}$

\section{CLINICAL INVESTIGATIONS OF THE IMPACT OF VITAMIN D ON NATURAL HISTORY OF IBD}

Several studies on vitamin $\mathrm{D}$ supplementation have supported a beneficial effect of vitamin D in IBD. In the Nurses' Health Study cohort of 72719 individuals, women with the predicted highest vitamin D levels had a significantly lower risk of incident Crohn's disease. ${ }^{11}$ Moreover, a cross-sectional study reported an inverse association between s-25(OH)D and disease activity in 182 patients with Crohn's disease, ${ }^{19}$ as patients with quiescent disease had a significant higher median $\mathrm{s}-25(\mathrm{OH}) \mathrm{D}$ levels than those with active disease. Furthermore, a case-control study in patients with IBD investigated colonic biopsies using immunohistochemistry showing a decreased VDR expression in areas with a high histological evidence of inflammation. $^{20}$

To address the causation question, a prospective study of 70 patients with ulcerative colitis in clinical remission followed for 1 year reported that a s-25(OH)D level below $87.5 \mathrm{nmol} / \mathrm{L}$ was associated with an increased risk of flaring disease. ${ }^{21}$ Similarly, a prospective 5-year longitudinal study involving 965 patients with IBD found an association between vitamin $\mathrm{D}$ and health-related outcome. ${ }^{13}$ Low (ie, $<75 \mathrm{nmol} / \mathrm{L}) \quad 25(\mathrm{OH}) \mathrm{D}$ levels were monitored in $30 \%$ of patients at study entry ${ }^{13}$ and during the follow-up, and these patients required significantly more medications (glucocorticoids, biologicals and narcotics), CT scans, hospitalisations and surgery, than did those with $25(\mathrm{OH}) \mathrm{D}$ levels of $\geq 75 \mathrm{nmol} / \mathrm{L} .^{13}$ To further control for the effect of disease severity on $25(\mathrm{OH}) \mathrm{D}$ levels, a subgroup analysis of patients in clinical remission at study entry was performed. In this group, more patients with low versus normal $25(\mathrm{OH}) \mathrm{D}$ levels required either glucocorticoids $(51 \%$ and $37 \%$, respectively) or IBD-related surgery (34\% and 22\%, respectively). ${ }^{13}$ Moreover, among patients with low vitamin D levels who received vitamin D supplementation, a progressively reduced healthcare utilisation was observed during the 5-year follow-up, whereas those with low 25(OH)D levels without any such supplementation oppositely increased their healthcare utilisation. This extensive study with a comprehensive IBD cohort associated low s-25 $(\mathrm{OH}) \mathrm{D}$ to a multiplicity of outcomes and has added substantial information to the increasing amount of evidence between $25(\mathrm{OH}) \mathrm{D}$ levels and outcomes in IBD. ${ }^{15}$ Finally, another comprehensive prospective study of 3217 patients with IBD also revealed that low $25(\mathrm{OH}) \mathrm{D}$ (ie, $<50 \mathrm{nmol} / \mathrm{L}$ ) was associated with a higher risk of IBD-related surgery and hospitalisations and that patients with Crohn's disease who normalised their $25(\mathrm{OH}) \mathrm{D}$ level at the same time reduced the risk of IBD-related surgery. ${ }^{14}$

\section{RESPONSE TO BIOLOGICALS}

Only few studies have explored the relationship between $25(\mathrm{OH}) \mathrm{D}$ levels and the probability of remission while on a certain medication. However, among 37 patients with Crohn's disease, a rapid increase of s-25(OH)D was observed in responders to TNF inhibitors, ${ }^{22}$ and recently, similar observations were noticed in ulcerative colitis as well. ${ }^{23}$ Moreover, a single-centre cohort study of 101 patients with IBD revealed that pretreatment levels of $25(\mathrm{OH}) \mathrm{D}$ influenced durability of TNF inhibitors. ${ }^{24}$ This trial supported the relevance of both correcting and maintaining adequate vitamin $\mathrm{D}$ levels in $\mathrm{IBD} \geq 75 \mathrm{nmol} / \mathrm{L}$ to reduce the risk of flares and to optimise response to targeted medical regimens. ${ }^{24}$ Finally, a retrospective study on 384 patients with IBD treated with biologics concluded that IBD patients with normal s-25(OH)D levels at the initiation of treatment with a TNF inhibitor had a 2.6-fold increased chance of reaching remission within 3 months as compared with those patients with low vitamin D concentrations. ${ }^{23}$ Nevertheless, a Canadian prospective, randomised controlled clinical trial (RCT) in 28 patients with moderate to severe Crohn's disease scheduled for infliximab stratified patients into those having low (ie, $<75 \mathrm{nmol} / \mathrm{L}$ ) or normal s-25(OH) D levels. ${ }^{25}$ The patients got their induction therapy with infliximab, and at week 14 , vitamin D-deficient patients were supplemented with intramuscular cholecalciferol and reassessed at week 22. Unexpectedly, 
this study showed that those with low vitamin D levels had a higher rate of clinical remission than those with normal levels both at week 14 and week 22 (80\% vs $23 \%(\mathrm{p}=0.007)$ and $79 \%$ vs $17 \%(\mathrm{p}=0.005)$, respectively). ${ }^{25}$ There is no obvious explanation for this outcome, emphasising that there is still unclarified mechanistically issues about vitamin D in IBD. ${ }^{25}$

\section{VITAMIN D AS A THERAPY FOR IBD}

Experimental studies in mice have previously shown vitamin $\mathrm{D}$ to reduce the severity of colitis. ${ }^{26}$ In humans, vitamin D deficiency or impaired VDR signalling might worsen colitis through multiple effects, ${ }^{27}$ and vitamin $\mathrm{D}$ supplementation has been reported to increase both bacterial richness and diversity in favour of butyrate-producing microbiota ${ }^{28}$ (figure 1).

Nevertheless, only a few RCTs have examined the effects of vitamin D supplementation on outcome of IBD. In a small trial of Crohn's disease in remission, 94 patients were randomised to either $1200 \mathrm{IU}$ of vitamin D3 daily or similar placebo. The trial concluded that supplementation for 12 months modestly increased $\mathrm{s}-25(\mathrm{OH}) \mathrm{D}$ levels and non-significantly $(\mathrm{p}=0.06)$ reduced the proportion of patients with clinical relapse from $29 \%$ to $13 \% .^{29}$

Supplementing all patients with the same amount of vitamin D might, however, result in patients with a low basal level not reaching the therapeutic threshold. Nevertheless, this was not relevant in an intervention study on 18 patients with Crohn's disease ${ }^{30}$ who applied a design focusing on achieving $25(\mathrm{OH}) \mathrm{D}$ levels of $100 \mathrm{nmol} / \mathrm{L}$, instead of receiving a fixed daily dose of vitamin D. After 6 months, the authors reported a highly significant reduction in disease activity scores. Unfortunately, this study had certain shortcomings, including a very small study cohort and the lack of a control group. ${ }^{30}$

An RCT including 90 patients with quiescent ulcerative colitis ${ }^{31}$ compared effects of a single intramuscular injection of a very high vitamin D dose (300 000 IU) with an intramuscular injection of $1 \mathrm{~mL}$ saline (placebo). Systemic inflammation, measured as level of serum CRP, was assessed 3 months after intervention showing a decrease in the group receiving vitamin D3. ${ }^{31}$

To address some of the problems with under-dosing of vitamin $\mathrm{D}$ in different trials, a recent prospective pilot study of 10 patients with active IBD and a s-25 $(\mathrm{OH}) \mathrm{D}$ level $<75 \mathrm{nmol} / \mathrm{L}$ used oral doses of 5000-10 000 U/ day. Dose adjustments were performed 4 weekly, aiming at a target level of $100-126 \mathrm{nmol} / \mathrm{L}$. Peroral doses used in the protocol were 5000-10 000 U/day. Over the 12 weeks of the study, the mean increase was $50 \mathrm{nmol} / \mathrm{L}(20 \mathrm{ng} / \mathrm{mL})$, with most patients needing at least one 4-week period of $10000 \mathrm{U} /$ day. Target or near-target was achieved in all participants over 12 weeks, and though a signal for hypercalciuria was

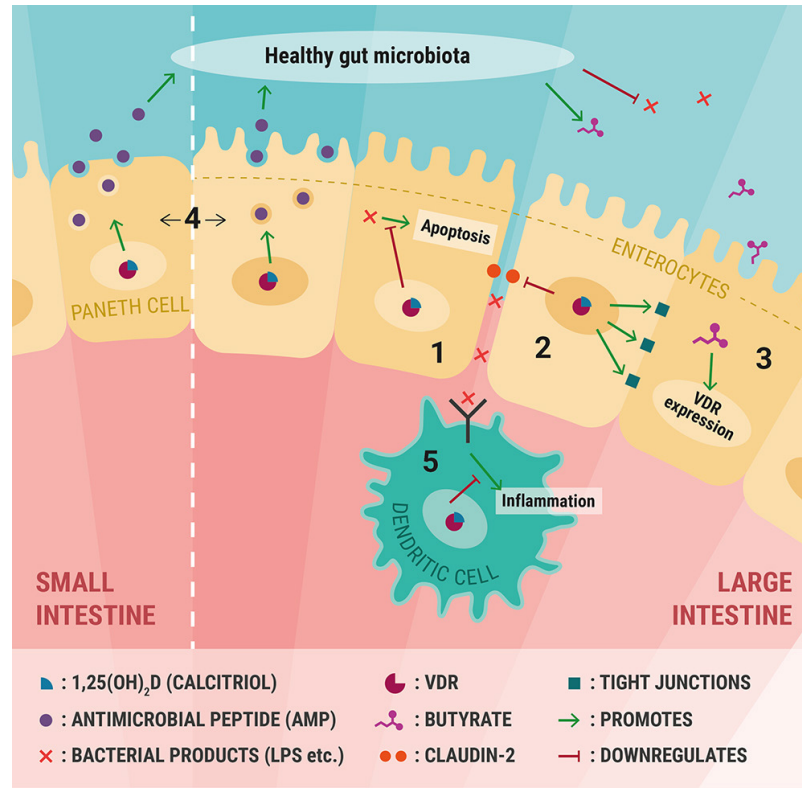

Figure 1 Epithelial mechanisms of vitamin D: (1) increased VDR activity is shown to repress NF- $\kappa B$-dependent epithelial apoptosis pathways in experimental colitis. (2) Claudin-2 (CL-2), a paracellular cation channel involved in barrier formation, seems to be affected by vitamin $D$, although the precise mechanism needs to be further revealed. An increased expression of $\mathrm{CL}-2$ is observed in the inflamed intestine, which in turn is downregulated by treatment with $1,25(\mathrm{OH})_{2} \mathrm{D}$. Low $\mathrm{s}-1,25(\mathrm{OH})_{2} \mathrm{D}$ in patients with IBD is associated with decreased expression of zonula occludens 1 (a tight junction protein) and E-cadherin (an adherins junction component). Moreover, caco2 , a colorectal cancer cell line, upregulate tight junction proteins on 1,25(OH) 2 D stimulation. (3) Treatment with bacterial product butyrate in human colonic cell lines increase VDR expression significantly. (4) Secretion of cathilicidin-related antimicrobial peptide (cAMP) and other AMPs, such as $\alpha$-defensins from ileal Paneth cells and $\beta$-defensins from colonocytes, are seemingly key factors in regulation of the microbiota. VDR is known to increase AMP expression as well as to negate a pathogen-induced inhibition of CAMP expression. Absence of VDR does also affect lysosomal function and autophagy in the gut epithelium, thus signifying a role of VDR in microbial regulation. (5) VDR plays a role in the antigen presenting function in dendritic cells and thereby in the modulation of their immunological response. VDR activation leads to decreased IL-10/IL-12 ratios, thus favouring maturation of regulatory $T$ cells and thereby decreasing the proinflammatory response. IBD, inflammatory bowel disease; IL, interleukin.

noted in one patient, the regimen was well tolerated, and symptom-based activity scores improved. ${ }^{32}$

A recent prospective study evaluated subjective and objective markers of intestinal inflammation as well as the faecal microbiota, following vitamin D replacement in patients with active and inactive ulcerative colitis and in non-IBD controls. ${ }^{33}$ Vitamin D deficiency was defined by $25(\mathrm{OH}) \mathrm{D}<50 \mathrm{nmol} / \mathrm{L}$. Twenty-five individuals participated (eight with active disease, nine with quiescent disease as well as eight non-IBD controls). The study showed for the first time that replacement with $40000 \mathrm{IU}$ vitamin $\mathrm{D}_{3}$ once weekly for 8 weeks in patients with active ulcerative colitis improved 
objective markers of inflammation, including faecal calprotectin, platelet counts, albumin as well as disease activity scores. However, the overall microbiota diversity was unchanged, suggesting that vitamin $\mathrm{D}$ reduces intestinal inflammation independently of faecal bacterial composition. ${ }^{33}$

Although the available studies have confounders or limitations (eg, variation in cut-off levels of s-25 $(\mathrm{OH})$ $\mathrm{D}$ values used to define 'deficiency'; differences in study populations and designs, including inclusion and exclusion criteria as well as activity scores applied; treatment doses; and outcomes) and as direct comparisons between studies are complicated by the lack of a standardisation between various assays used to measure $25(\mathrm{OH}) \mathrm{D}$ levels, ${ }^{27}$ they seem to support the concept of vitamin $\mathrm{D}$ having anti-inflammatory effects in IBD. ${ }^{12} 14$

\section{PRACTICAL APPROACH TO VITAMIN D SUPPLEMENTATION FOR PATIENTS WITH IBD IN CLINICAL SETTING}

When choosing the right strategy for vitamin D supplementation in IBD, several factors must be considered, including disease activity, degree of deficit, malabsorption, obesity, compliance and sun-exposure habits.

Vitamin D levels are intimately linked with IBD disease activity. and their association is likely a dynamic process. Vitamin D levels are disproportionately low among IBD patients with active inflammation. ${ }^{34}$ Low vitamin $\mathrm{D}$ levels may increase the risk of future IBD clinical relapse, ${ }^{1324}$ while treating IBD flares results in increased vitamin D levels. ${ }^{25}$ As such, it is important to first consider the disease activity of an IBD patient prior to formulating a plan to optimise vitamin $D$ levels. Given that IBD patients with disease flares are at high risk of developing malabsorption and vitamin $\mathrm{D}$ deficiency, we propose that a higher initial bolus dose be administered, and malabsorption should be tested among IBD patients with active disease (figure 2).

Despite no 'gold standard' for adequate s-25(OH)D levels in IBD exist, most data suggest that a s-25(OH) D level $>75 \mathrm{nmol} / \mathrm{L}$ is beneficial compared with IBD patients with s-25(OH)D $<50 \mathrm{nmol} / \mathrm{L}$ in terms of level of inflammatory markers and clinical scores. ${ }^{16}$

Symptomatic vitamin D intoxication (causing hypercalcaemia and renal calcifications) is very rare and has in most instances only been reported in people with $\mathrm{s}-25(\mathrm{OH}) \mathrm{D}$ levels above $4-500 \mathrm{nmol} / \mathrm{L}$. An increased risk of adverse events, however, appears to be related to levels of s-25(OH)D levels $>200 \mathrm{nmol} / \mathrm{L}$. ${ }^{27}$ Accordingly, based on our current knowledge, it seems reasonable to aim at targeting $\mathrm{s}-25(\mathrm{OH}) \mathrm{D}$ levels in the range of $75-125 \mathrm{nmol} / \mathrm{L}$.

From a pharmacokinetic point of view, daily and weekly oral dosing as well as providing vitamin D as a large oral or intramuscular bolus dose (months apart) has been shown to be effective in maintaining s-25(OH) $\mathrm{D}$ at a replete level. However, although intramuscular bolus injections tend to reach the same level as an equal total oral dose, the increase in s-25(OH)D levels occur with a month of delay following injection therapy. ${ }^{35}$ Furthermore, providing vitamin D as a large oral or intramuscular bolus dose has been shown to increase risk of falls and fractures in RCTs. ${ }^{36}{ }^{37}$ As a consequence, the US Preventive Services Task Force as well as others have recently called for caution on use of high-dose vitamin D supplementation. ${ }^{38} 39$ Providing vitamin D supplementation as a daily dose is therefore the preferred option.

As a rule of thumb, s-25(OH)D levels will increase by approximately $1 \mathrm{nmol} / \mathrm{L}$ per $1 \mu \mathrm{g}$ (40 IU) of daily vitamin D3 supplementation. ${ }^{40}$ The effect is relatively more pronounced in vitamin $\mathrm{D}$ insufficient as compared with vitamin D-replete individuals, whereas the response decreases with increased body weight. ${ }^{41}$ Moreover, comparing the two most common vitamin D forms, ergo- (D2) and cholecalciferol (D3), cholecalciferol seems more potent than ergocalciferol when supplemented as a large oral bolus. ${ }^{41}$

Accordingly, the daily dose of vitamin $\mathrm{D}$ supplementation (in $\mu \mathrm{g}$ ) needed to obtain a s-25(OH)D level in the target range (eg, $100 \mathrm{nmol} / \mathrm{L}$ ) can be estimated as 100 minus measured s-25(OH)D level. Serum 25(OH) D levels should be remeasured after 3-4 months. If not in the target range and a lack of compliance cannot be excluded, it may be considered to recommend intake of vitamin D supplements on a weekly basis in a dose equal to the calculated daily dose. If still not in target range, a vitamin $\mathrm{D}$ absorption test may be performed by providing the patient a large oral dose (eg, 100 000-300 $000 \mathrm{IU}$ ) of vitamin D. In response to such a high dose, a considerable increase in s-25(OH) $\mathrm{D}$ level is to be expected within 2-4weeks. ${ }^{42}$ In order to assure compliance, the bolus dose should be provided under the supervision of a healthcare professional. If a response is achieved following a large oral bolus, the most likely explanation for lack of an effect of daily/weekly dosing is low compliance or relative malabsorption. If so, daily/weekly dose of vitamin $\mathrm{D}$ may be increased (doubled/tripled) to determine whether this may result in a s-25(OH)D level within the target range. If a substantial increase in $\mathrm{s}-25(\mathrm{OH})$ $\mathrm{D}$ levels is not achieved in response to a large bolus, severe malabsorption should, however, be considered. Intramuscular vitamin $\mathrm{D}$ injections may accordingly be needed, but this should be considered as a last option. Increased sun exposure or use for sunbeds may be considered as an alternative option. Patients should be fully informed that each episode of sun(-bed) exposure should only be for such a short time, due to a potential increased risk of skin malignancies. Time of year should be considered, as the dose of vitamin D needed to maintain a replete vitamin D status may be lower during summertime. For the same reason, we recommend measuring $25(\mathrm{OH}) \mathrm{D}$ levels at least annually (preferably during wintertime) and more frequently in 


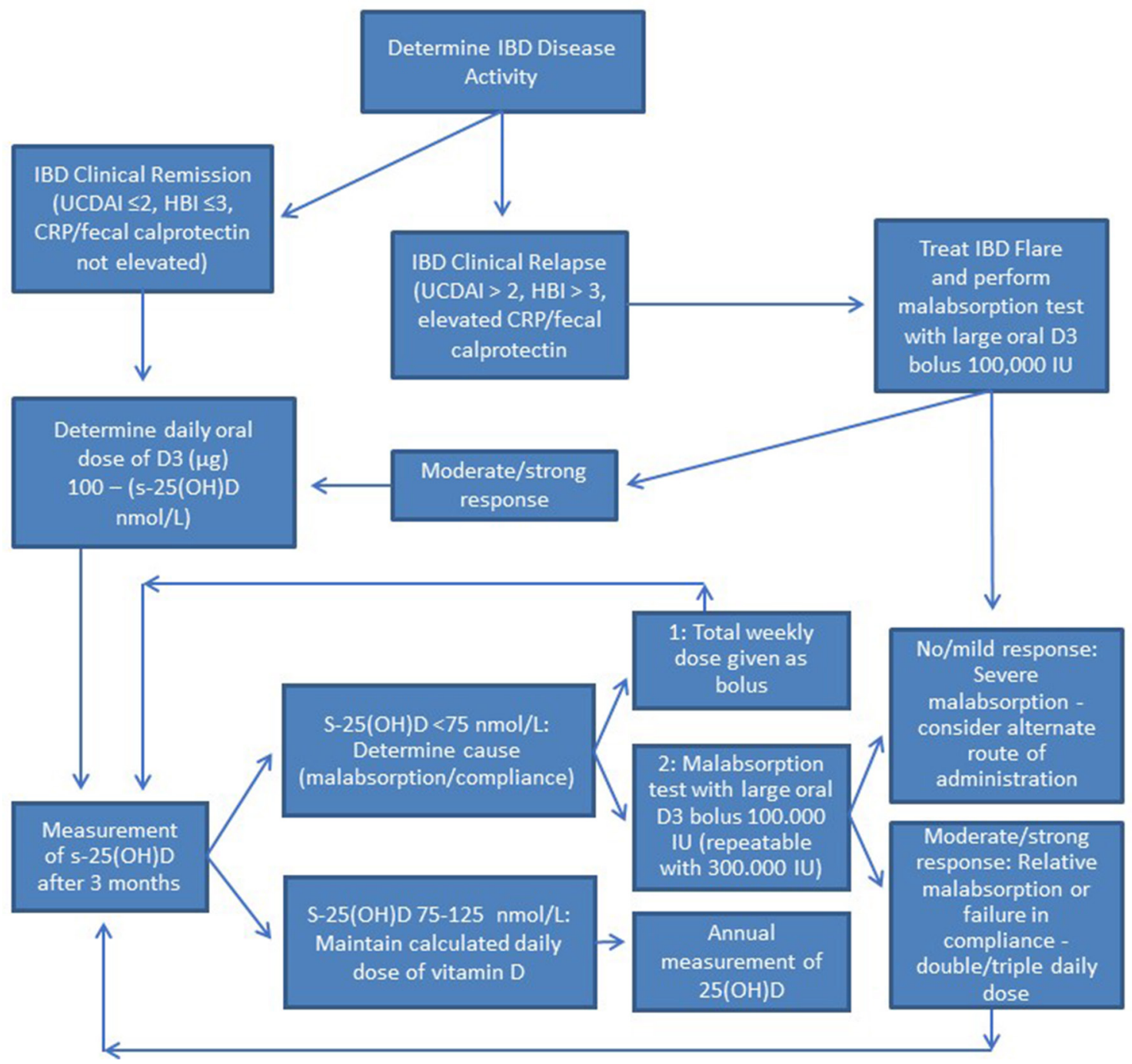

Figure 2 Approach to 25(OH)D supplementation in patients with IBD. Determining adequate daily dose as (target s-25(OH)D level current s-25(OH)D level) $\mu \mathrm{g}$. If target level is not reached within 3 months, administration as weekly bolus should be tried. If current level continues <target level, malabsorption should be considered. CRP, C reactive protein; HBI, Harvey Bradshaw Index; IBD, inflammatory bowel disease; UCDAl, Ulcerative Colitis Disease Activity Index.

case of insufficiency and/or during disease exacerbation (on a 3-4-monthly basis).

Our suggestions regarding optimising $25(\mathrm{OH}) \mathrm{D}$ levels with supplementation in patients with IBD need, however, to be interpreted with caution due to the lack of long-term RCTs on effects of vitamin D supplementation in IBD.

\section{CONCLUSIONS AND RECOMMENDATIONS}

It is still unclear whether vitamin D deficiency is a causative factor for IBD. However, vitamin D deficiency seems to be prevalent in IBD and to be inversely linked to disease activity, more frequent relapses, higher postoperative recurrence, poorer quality of life and in general an abnormal response to biologicals as compared with patients with normal or high s-25(OH) D levels. ${ }^{16}$ Nevertheless, further research is needed to define the optimal therapeutic level of $25(\mathrm{OH}) \mathrm{D}$ in IBD (ie, should other thresholds be recommended for extraskeletal benefits) or if other paraclinical tests should be introduced like vitamin D binding protein and free and bioavailable vitamin D and to clarify how vitamin $\mathrm{D}$ modifies levels of inflammation and its exact effect on disease severity. It should additionally be assessed if differences exist in vitamin D metabolism and absorption in IBD. Furthermore, interventions should focus on vitamin $\mathrm{D}$ levels during asymptomatic periods, when possible, to avoid confounding and investigating its potential synergy with current and future therapies in IBD.

Cumulatively, the available data support that vitamin $\mathrm{D}$ appears to be an intimate player in the pathogenesis of IBD at both the cellular and phenotypic level and its potential role as a therapeutic agent in improving the disease state in these patients, even though available knowledge is based on indirect evidence. Thus, it is uncertain if causation will ever be equivocally established, as no industrial sponsors might be interested 
to fund appropriately sized RCTs of vitamin D supplementation in an intervention cohort with an unpatented drug.

As mentioned, it seems reasonable to offer patients with IBD measurements of s-25(OH)D levels at least once a year (preferable during winter). We have provided for the reader a flow chart for vitamin D supplementation with a relatively affordable and accessible medication and subsequent follow-ups. Such efforts may increase the probability of bringing the IBC into clinical remission, and to conventional therapeutic strategies and in this way lead to better patient outcomes as well as reduced healthcare expenses.

Contributors The authors' responsibilities were as follows: OHN wrote first draft of the manuscript; TIH, JMG, KBJ and LR subsequently added and revised the manuscript. All authors read and approved the final manuscript. None of the authors reported a conflict of interest related to the study.

Funding The authors have not declared a specific grant for this research from any funding agency in the public, commercial or not-for-profit sectors.

Competing interests None declared.

Patient consent Not required.

Provenance and peer review Not commissioned; externally peer reviewed.

Open access This is an open access article distributed in accordance with the Creative Commons Attribution Non Commercial (CC BY-NC 4.0) license, which permits others to distribute, remix, adapt, build upon this work noncommercially, and license their derivative works on different terms, provided the original work is properly cited, appropriate credit is given, any changes made indicated, and the use is noncommercial. See: http://creativecommons.org/licenses/by-nc/4. $0 /$.

\section{REFERENCES}

1 Larsen S, Bendtzen K, Nielsen OH. Extraintestinal manifestations of inflammatory bowel disease: epidemiology, diagnosis, and management. Ann Med 2010;42:97-114.

2 Nielsen $\mathrm{OH}$, Soendergaard C, Vikner ME, et al. Rational management of iron-deficiency anaemia in inflammatory bowel disease. Nutrients 2018;10:82-E93.

3 Holick MF. Vitamin D deficiency. N Engl J Med Overseas Ed 2007;357:266-81.

4 Rosen CJ. Clinical practice. Vitamin D insufficiency. N Engl J Med 2011;364:248-54.

5 van Etten E, Mathieu C. Immunoregulation by 1,25-dihydroxyvitamin D3: basic concepts. J Steroid Biochem Mol Biol 2005;97:93-101.

6 D'Ambrosio D, Cippitelli M, Cocciolo MG, et al. Inhibition of IL-12 production by 1,25-dihydroxyvitamin D3. Involvement of NF-kappaB downregulation in transcriptional repression of the $\mathrm{p} 40$ gene. J Clin Invest 1998;101:252-62.

7 Alroy I, Towers TL, Freedman LP. Transcriptional repression of the interleukin-2 gene by vitamin D3: direct inhibition of NFATp/AP-1 complex formation by a nuclear hormone receptor. Mol Cell Biol 1995;15:5789-99.

8 Mudambi K, Bass D. Vitamin D: a brief overview of its importance and role in inflammatory bowel disease. Transl Gastroenterol Hepatol 2018;3:31-6.

9 Khoo AL, Chai LY, Koenen HJ, et al. Regulation of cytokine responses by seasonality of vitamin D status in healthy individuals. Clin Exp Immunol 2011;164:72-9.
10 Chetcuti Zammit S, Ellul P, Girardin G, et al. Vitamin D deficiency in a European inflammatory bowel disease inception cohort: an Epi-IBD study. Eur J Gastroenterol Hepatol 2018;30:1297-303.

11 Ananthakrishnan AN, Khalili H, Higuchi LM, et al. Higher predicted vitamin D status is associated with reduced risk of Crohn's disease. Gastroenterology 2012;142:482-9.

12 Frigstad SO, Høivik M, Jahnsen J, et al. Vitamin D deficiency in inflammatory bowel disease: prevalence and predictors in a Norwegian outpatient population. Scand I Gastroenterol 2017;52:100-6.

13 Kabbani TA, Koutroubakis IE, Schoen RE, et al. Association of vitamin $\mathrm{D}$ level with clinical status in inflammatory bowel disease: a 5-year longitudinal study. Am J Gastroenterol 2016;111:712-9.

14 Ananthakrishnan AN, Cagan A, Gainer VS, et al. Normalization of plasma 25-hydroxy vitamin D is associated with reduced risk of surgery in Crohn's disease. Inflamm Bowel Dis 2013;19:1921-7.

15 Ananthakrishnan AN. Editorial: vitamin D and IBD: can we get over the "causation" hump? Am J Gastroenterol 2016;111:720-2.

16 Nielsen OH, Rejnmark L, Moss AC. Role of Vitamin D in the Natural history of inflammatory bowel disease. J Crohns Colitis 2018;12:742-52.

17 Holick MF, Binkley NC, Bischoff-Ferrari HA, et al. Evaluation, treatment, and prevention of vitamin D deficiency: an Endocrine Society clinical practice guideline. J Clin Endocrinol Metab 2011;96:1911-30.

18 Institute of Medicine (US) Committee to Review Dietary Reference Intakes for Vitamin D and Calcium. Dietary Reference Intakes for Vitamin D and Calcium. Washington (DC): National Academic Press (US), 2011.

19 Jørgensen SP, Hvas CL, Agnholt J, et al. Active Crohn's disease is associated with low vitamin D levels. J Crohns Colitis 2013;7:e407-e413.

20 Abreu-Delgado Y, Isidro RA, Torres EA, et al. Serum vitamin D and colonic vitamin D receptor in inflammatory bowel disease. World J Gastroenterol 2016;22:3581-91.

21 Gubatan J, Mitsuhashi S, Zenlea T, et al. Low Serum Vitamin D during remission increases risk of clinical relapse in patients with ulcerative colitis. Clin Gastroenterol Hepatol 2017;15:240-6.

22 Ham M, Longhi MS, Lahiff C, et al. Vitamin D levels in adults with Crohn's disease are responsive to disease activity and treatment. Inflamm Bowel Dis 2014;20:856-60.

23 Winter RW, Collins E, Cao B, et al. Higher 25-hydroxyvitamin $D$ levels are associated with greater odds of remission with anti-tumour necrosis factor- $\alpha$ medications among patients with inflammatory bowel diseases. Aliment Pharmacol Ther 2017;45:653-9.

24 Zator ZA, Cantu SM, Konijeti GG, et al. Pretreatment 25 -hydroxyvitamin D levels and durability of anti-tumor necrosis factor- $\alpha$ therapy in inflammatory bowel diseases. JPEN J Parenter Enteral Nutr 2014;38:385-91.

25 Reich KM, Fedorak RN, Madsen K, et al. Role of Vitamin D in Infliximab-induced Remission in Adult Patients with Crohn's Disease. Inflamm Bowel Dis 2016;22:92-9.

26 Daniel C, Radeke HH, Sartory NA, et al. The new low calcemic vitamin D analog 22-ene-25-oxa-vitamin D prominently ameliorates $\mathrm{T}$ helper cell type 1 -mediated colitis in mice. J Pharmacol Exp Ther 2006;319:622-31.

27 Ebeling P, Adler R, Jones G, et al. Management of endocrine disease: therapeutics of vitamin D. Eur J Endocrinol 2018;179:R239-59.

28 Olsen KS, Aksnes L, Frøyland L, et al. Vitamin D status and PUFA ratios in a national representative cross-section of healthy, middle-aged Norwegian women-the Norwegian Women and Cancer Post-Genome Cohort. Scand J Public Health 2014;42:814-20. 
29 Jørgensen SP, Agnholt J, Glerup H, et al. Clinical trial: vitamin D3 treatment in Crohn's disease - a randomized doubleblind placebo-controlled study. Aliment Pharmacol Ther 2010;32:377-83.

30 Yang L, Weaver V, Smith JP, et al. Therapeutic effect of vitamin $\mathrm{d}$ supplementation in a pilot study of Crohn's patients. Clin Transl Gastroenterol 2013;4:e33.

31 Sharifi A, Hosseinzadeh-Attar MJ, Vahedi H, et al. A randomized controlled trial on the effect of vitamin D3 on inflammation and cathelicidin gene expression in ulcerative colitis patients. Saudi J Gastroenterol 2016;22:316-23.

32 Garg M, Rosella O, Rosella G, et al. Evaluation of a 12-week targeted vitamin D supplementation regimen in patients with active inflammatory bowel disease. Clin Nutr 2018;37:1375-82.

33 Garg M, Hendy P, Ding JN, et al. The effect of Vitamin D on Intestinal Inflammation and Faecal Microbiota in Patients with Ulcerative Colitis. J Crohns Colitis 2018;12:963-72.

34 Del Pinto R, Pietropaoli D, Chandar AK, et al. Association between inflammatory bowel disease and vitamin D deficiency: a systematic review and meta-analysis. Inflamm Bowel Dis 2015;21:2708-17.

35 Wylon K, Drozdenko G, Krannich A, et al. Pharmacokinetic evaluation of a single intramuscular high dose versus an oral long-term supplementation of cholecalciferol. PLoS One 2017;12:e0169620.
36 Bischoff-Ferrari HA, Dawson-Hughes B, Orav EJ, et al. Monthly high-dose vitamin D treatment for the prevention of functional decline: a randomized clinical trial. JAMA Intern Med 2016;176:175-83.

37 Sanders KM, Stuart AL, Williamson EJ, et al. Annual highdose oral vitamin D and falls and fractures in older women: a randomized controlled trial. JAMA 2010;303:1815-22.

38 Gallagher JC. Vitamin D and falls - the dosage conundrum. Nat Rev Endocrinol 2016;12:680-4.

39 Guirguis-Blake JM, Michael YL, Perdue LA, et al. Interventions to prevent falls in older adults: updated evidence report and systematic review for the us preventive services task force. JAMA 2018;319:1705-16.

40 Heaney RP, Davies KM, Chen TC, et al. Human serum 25-hydroxycholecalciferol response to extended oral dosing with cholecalciferol. Am J Clin Nutr 2003;77:204-10.

41 Oliveri B, Mastaglia SR, Brito GM, et al. Vitamin D3 seems more appropriate than D2 to sustain adequate levels of 25OHD: a pharmacokinetic approach. Eur J Clin Nutr 2015;69:697-702.

42 Bacon CJ, Gamble GD, Horne AM, et al. High-dose oral vitamin D3 supplementation in the elderly. Osteoporos Int 2009;20:1407-15. 